\title{
$O$ caráter sociocognitivo da metaforicidade: contribuições do estudo do tratamento de expressões formulaicas por pessoas com afasia e com Doença de Alzheimer
}

The sociocognitive nature of metaphor: input from formulaic expressions in aphasic and Alzheimer patients

\author{
Edwiges Maria Morato \\ UNICAMP
}

\begin{abstract}
In order to characterize the role of socio-cognitive dimensions of language in the context of aphasia and Alzheimer's Disease (AD), we intend to analyze linguistic and interactive aspects related to the process of interpretation of formulaic expressions by subjects with $\mathrm{AD}$ and also by subjects with aphasia both in their initial phases. Our data shows that subjects with aphasia and subjects with DA, in parallel with what happens in other contexts, operate a "metaphoric calculus" of expression's meaning considering the context of production and pragmatic rules. Besides, our data also reveal that metaphors proper of formulaic expressions are understood by these subjects with the help of other cognitive processes and also because of their interpretative expectations of linguistic regularities relative to the "metaphoric calculus".
\end{abstract}

Keywords

Formulaic expressions; Metaphoric calculus; Aphasia; Alzheimer's Disease. 


\section{Resumo}

Nosso objetivo é analisar aspectos lingüístico-interacionais da interpretação de expressões formulaicas por pessoas com afasia e com Doença de Alzheimer (DA) em fase inicial, a fim de melhor caracterizar a dimensão sociocognitiva da linguagem e seu papel no contexto de ambas as patologias. Nossos dados indicam que, à maneira do que ocorre em contextos não patológicos, sujeitos com afasia e com DA não apenas procedem a uma espécie de "cálculo metafórico" da identificação do significado da expressão a partir da situação de uso e normas pragmáticas relativas às expressões: nossos dados mostram também que a metaforicidade é apreendida pelos sujeitos com o concurso de outros processos cognitivos e mediante expectativas interpretativas que eles nutrem em relação às regularidades linguiísticas atinentes ao cálculo aludido acima.

\section{Palavras-chave}

Metaforicidade; Expressões formulaicas; Afasia; Doença de Alzheimer. 


\section{Introdução}

endo como pano de fundo uma discussão sobre processos lingüísticos e sociocognitivos envolvidos na metaforicidade, pretendemos discutir neste artigo o que nos estudos neurocognitivos tem sido tradicionalmente afirmado como forma de consagrar uma dicotomia entre o lingüístico e o cognitivo: que as afasias são ou se devem essencialmente a um problema lingüístico (isto é, metalingüístico) e que as neurodegenerescências (como a Doença de Alzheimer) são ou se devem a um problema essencialmente cognitivo, istoé, conceitual, psicológico, não lingüístico.

Uma boa maneira de problematizar essa dicotomia é postular, com base em uma perspectiva sociocognitiva de base vygotskiana, uma relação dialética entre o lingüístico e o cognitivo no tratamento da significação, plasmados no contexto enunciativo, isto é, instanciados em práticas sociais com linguagem. Nesse contexto teórico, tomamos como premissa básica uma concepção enunciativa da relação entre linguagem e cognição, tal como estabelecida pelo interacionismo vygotskiano: não há possibilidades integrais de conteúdos cognitivos ou domínios do pensamento fora da linguagem e nem linguagem fora de processos ou práticas interativas humanas.

De acordo com Vygotsky (1934), sob condições psicossociais, interativas, um processo interpessoal pode ser internalizado e gerar coordenações intra-individuais, reestruturando e reorganizando a maneira de pensar e agir simbolicamente dos indivíduos - em função não apenas das ações que a linguagem permite ou implica, mas da ação mesma que ela é (MORATO, 1996).

A idéia de uma construção social da cognição (e, naturalmente, da linguagem) deriva ou se projeta a partir da idéia de uma auto/socioconstrução de conhecimentos por aqueles que participam conjuntamente de processos interacionais, multimodais, largamente mediados por linguagem. Assim, a observação das condições nas quais os sujeitos atuam interativamente para compreender e expressar processos simbólicos é fundamental para compreendermos não apenas a maneira como se 
dá a aquisição de conhecimentos novos ou a reestruturação de conhecimentos existentes, mas também o desenvolvimento da capacidade incessante que temos de compreender, refletir e "controlar" de alguma maneira os processos de significação.

Nessa perspectiva, linguagem e interação jogam um papel fundamental diante da constituição e da estruturação mesma da cognição, ${ }^{1}$ como demonstram no plano empírico os processos aquisicionais e os que envolvem a (re)organização lingüístico-cognitiva em contextos patológicos, como as afasias e as neurodegenerescências.

A cognição, tomada sempre em interação (uma tese vygotskiana) e na presença constitutiva da natureza enunciativa, intersubjetiva, dialógica da linguagem (outra tese vygotskiana), é também considerada nessa perspectiva como encarnada (embodied), isto é, indissociável de práticas corporais e gestuais (LAKOFF; JOHNSON, 1999; FAUCCONNIER; TURNER, 2002; MONDADA, 2003; MARCUSCHI, 2003; SALOMÃO, 1999; etc.)

No âmbito de tais considerações teóricas, o objetivo específico deste artigo é analisar aspectos lingüístico-interacionais da manipulação de expressões formulaicas (como idiomatismos e provérbios) por pessoas com afasia ${ }^{2}$ e com Doença de Alzheimer (DA) ${ }^{3}$ em fase inicial, a fim de melhor caracterizar a dimensão sociocognitiva da linguagem e seu papel no contexto de ambas as patologias - afasia e neurodegenerescência - cujas inter-relações são ainda controversas, se levarmos em conta as discussões projetadas no campo da literatura da área clínica.

Ainda que as alterações de linguagem nas demências sejam inadvertidamente chamadas de afasias, percebe-se uma tentativa recorrente nos estudos neurocognitivos de fornecer padrões diagnósticos diferenciados para o problema da linguagem em ambas as síndromes. ${ }^{4}$ Apenas recentemente, estudos dedicados ao tema têm admitido que a linguagem e processos afeitos a ela têm um papel decisivo diante do declínio cognitivo, bem como têm admitido que na heterogênea semiologia das afasias o problema de linguagem implica sempre e de alguma maneira uma questão cognitiva, relativa à memória, à percepção, à gestualidade, etc.

Contudo, ainda que afasia e neurodegenerescência digam respeito a quadros etiológicos e nosológicos distintos, os problemas de linguagem em ambos os contextos são freqüentemente similares, tais como dificuldades de acesso e processamento lexical, parafasias, intrusões, alterações gramaticais, repetições, 
uso abundante de dêiticos, pausas longas ou hesitações - assim como são semelhantes as resoluções encontradas pelos sujeitos frente a eles: reformulações, correções auto e heteroiniciadas, tentativas aproximativas de encontrar palavras ou proceder à atividade referencial, expressiva evocação de semioses nãoverbais, repetições, pausas, etc.

Nos últimos anos, contrariando a concepção localizacionista e estruturalista dos primeiros tempos da Afasiologia e da Neuropsicologia (cf. MORATO, 2001b), pesquisadores do campo das neurociências têm observado, por meio de estudos de neuroimagem em sujeitos normais (isto é, que não apresentam patologias córtico-cognitivas), que ambos os hemisférios cerebrais são ativados no tratamento da metaforicidade (BOTTINI et al, 1994; PAPAGNO, 2001). Além de assinalar a importância do hemisfério direito para o tratamento da linguagem (tido tradicionalmente como "menor" ou menos relevante do que o esquerdo), tais achados também admitem a existência de uma cooperação entre processos lingüísticos e cognitivos no "cálculo metafórico" feito pelos sujeitos diante dos processos de significação.

De todo modo, como as pesquisas neurocognitivas têm indicado nos últimos tempos que zonas cerebrais não têm correlação direta com processos de significação psicossociais, resta-nos, no campo da ciência da linguagem, explorar as possibilidades explicativas relativamente ao tema, com isso integrando mais e mais a Linguística - com seus pressupostos e métodos próprios - à agenda dos estudos sobre as relações entre linguagem, cérebro e cognição.

\section{A questão da metaforicidade no contexto das afasias e das neurodegene-rescências: o caso das expressões formulaicas}

Segundo Amossy \& Pierrot (1997), "locuções, estereótipos e clichês fazem parte de um continuum de expressões cristalizadas, como os provérbios e os slogans, que se caracterizam pelo fato de que a cristalização atinge o enunciado todo". Pertencendo à classe de fenômenos de estereotipia, tais expressões respondem sociocognitivamente e de forma variada às restrições (necessárias e/ou suficientes) de cristalização lingüístico-discursiva. Essa cristalização, que pode ser entendida como provisória dada sua contingência histórica, depende também de várias formas de funcionamento da memória 
(histórica, social, discursiva, semântica, pessoal). O caráter formulaico dessas expressões é garantido em especial pela força da tradição cultural e pela remissão a representações, pressupostos ou pré-construídos reconhecidos, compartilhados ou renovados pelos falantes em situações socialmente situadas (cf. MARCUSCHI, 2003).

Com base nessa consideração, as locuções idiomáticas e os enunciados paremiológicos têm se mostrado, assim como a metáfora e outros fenômenos concernentes ao sentido, altamente interessantes para o estudo das relações entre linguagem e cognição, sobretudo ao focalizar gestos interpretativos dos falantes para dar conta do uso conotativo e figurado da linguagem em situações de práticas lingüísticas cotidianas.

Integrando as ditas locuções expressivas, o provérbio e o idiomatismo também têm sido considerados "estereótipos lingüísticos” (PLANTIN, 1993; AMOSSY; PIERROT, 1997; SCHAPIRA, 1999), ${ }_{5}^{5}$ por meio dos quais os interlocutores atuam no mundo de maneira retórica, performativa, argumentativa. $O$ percurso sociocognitivo desses estereótipos é garantido pela maneira alusiva, analógica, figurada com que os falantes manipulam enunciativamente a relação entre língua e realidade.

As expressões formulaicas, enquanto sintagmas metafóricos, podem ser entendidas como metáforas num sentido amplo. ${ }^{6}$ Segundo Lakoff, mesmo que as metáforas sejam ancoradas em corpos parecidos e em práticas cotidianas parecidas, em geral os indivíduos não são conscientes das metáforas que pensam ou mobilizam enunciativamente. Posto isso, o que vai interessar ao autor é o que também nos interessa a todos como seres cognitivos: o pensamento metafórico refletido na linguagem e que pode ser estudado pela linguagem (1997, p. 166). Tal arrazoado afasta-nos das abordagens cognitivistas do componente metafórico que, ao privilegiar em sua análise as estruturas conceptuais que estariam subjacentes à língua, acabam por negligenciar fatores lingüísticos constitutivos de sua construção. Moura, criticando o conceptualismo no estudo da metáfora, afirma:

Como as metáforas são indeterminadas, o trabalho de interpretação dos falantes é também uma operação de reconstrução lingüística. A meu ver, isso mostra que somente uma articulação das operações lingüísticas e conceptuais em jogo pode explicar como os falantes, em situações concretas de uso, tentam delimitar um sentido para as metáforas a que são expostos (MOURA, 2003, p. 11). 
Se considerarmos o funcionamento integrado de processos lingüísticos e cognitivos na construção do sentido, a metaforicidade não poderá ser explicada em termos de mera substituição de significantes, algo que se realizaria apenas no interior da significação lingüística; antes, ela se constitui de forma a responder pelo sentido de maneira sociocognitiva, articulando a um só tempo práticas e convenções de uso da linguagem, proposição metafórica e regularidades lingüísticas. A propósito disso, vejamos a seguinte passagem de Pires de Oliveira (1997):

O julgamento de literalidade ou metaforicidade, assim como a própria interpretação, é guiado pela combinação de uma série de parâmetros: o conhecimento da língua, o conhecimento de mundo, a referência a um tópico conversacional, o conhecimento sobre as condições da enunciação, o conhecimento mútuo entre os interlocutores (...) Um intérprete atribui a outro intérprete toda uma gama de crenças e conhecimentos.

Em estudos individuais e coletivos (MORATO, 2001a, 2005a; 2005b; MORATO et al., 2005; CAZELATO, 2003; BOLDRINI, 2004) a respeito das expressões formulaicas no contexto das afasias, temos observado que a linguagem pouco atua com força cognitivamente (re)construtora fora de situações enunciativas que caracterizam o emprego desses sintagmas metafóricos situados contextual e historicamente. Longe de sugerir uma dicotomia entre linguagem e metalinguagem, essa ponderação restitui à "linguagem em uso" seu caráter reflexivo e, aos sujeitos em interação, uma postura meta que os faz "observadores" (cf. AUTHIERRÉVUZ, 1998) mais ou menos conscientes de seus atos enunciativos, e também dos de seus interlocutores.

Em estudos realizados anteriormente, Cazelato (2003) e Boldrini (2004) observaram que, instados a interpretar e a empregar contextualmente um conjunto de expressões idiomáticas e de enunciados proverbiais, sujeitos afásicos, à maneira de sujeitos não afásicos de perfil sociolingüístico semelhante ao do grupo estudado, raramente se pautaram sobre o significado composicional das expressões ou se perturbaram de forma expressiva com o grau de metaforicidade dos enunciados, constituídos de provérbios com graus de metaforicidade distintos, isto é, tidos como mais e menos metafóricos. ${ }^{7}$ Antes, os sujeitos preferencialmente se ativeram à familiaridade semântico-pragmática que demonstravam com as referidas expressões que, por serem fenômenos 
essencialmente performativos, não podem ser analisadas como meramente lógico-inferenciais (cf. CAZELATO, 2003).

Temos observado, em relação às afasias, que problemas metalingüísticos stricto sensu (como as dificuldades de seleção lexical ou de processamento de categorias gramaticais, por exemplo) não destroem a capacidade de operar com elementos metafóricos; do mesmo modo, a instabilidade cognitiva que caracteriza os quadros de declínio cognitivo (irrelevância interpretativa, tendência para intrusões, circunlóquios, confabulações, digressões, etc.), se interfere nos gestos interpretativos requeridos no reconhecimento da metaforicidade, não parece ser capaz de explicá-los inteiramente ou mesmo de - por si mesma-impedi-los.

Em relação ao tratamento da metaforicidade, o que, afinal, poderia ser comum a ambos os quadros neurocognitivos aqui mencionados? Com base no enfoque interacionista brevemente exposto, poderíamos dizer no tocante a essa questão que seria: i) o caráter intersubjetivo, metaenunciativo e contextualmente situado da linguagem no reconhecimento e na expressão da metaforicidade, e ii) o papel co-construtor do interlocutor na referência metafórica. Por outro lado, o que parece ser distinto nos dois quadros é a ênfase que se coloca nos vários processos - lingüísticos, inferenciais, contextuais, mnêmicos - que atuam na significação metafórica.

No caso das afasias, o sujeito costumeiramente enfrenta no campo mesmo da linguagem suas dificuldades metalingüísticas (reparos, reformulações, riqueza prosódica, repetições, hesitações, utilização de promptings orais do interlocutor, etc.); além disso, ele lança mão de semioses não-verbais (como gestos, direcionamento do olhar, postura corporal, etc.) que atuam de maneira solidária à linguagem na configuração ou na interpretação da referência metafórica. No caso das demências, em que as atividades epilingüísticas estariam mais severamente alteradas (cf. DAMASCENO, 2000), o caráter regulador da linguagem vai depender acentuadamente de processos interlocutivos, interacionais, aumentando o papel do interlocutor na qualidade da autonomia enunciativa do sujeito e na relevância de seus processos de significação, bem como na adequada estruturação (textual, conversacional, contextual, pragmática, cognitiva) da interação.

Os enunciados formulaicos, bem como outras formas metaenunciativas, (modalizações, discursos relatados, ironias, etc.), mostram-se interessantes para a discussão que se enseja aqui por conta de dois fenômenos lingüísticocognitivamente interligados - o da enunciação e o da metalinguagem - que 
envolvem durante a interlocução ações reflexivas dos sujeitos sobre a linguagem (e sobre a interação). Vejamos alguns exemplos que podem aprofundar nossa discussão.

\section{Exemplificação}

Em estudos nos quais é solicitado aos sujeitos com afasia e com Doença de Alzheimer em estado inicial que expliquem o sentido de determinada expressão idiomática ou enunciado proverbial e que imaginem uma situação na qual caberia seu uso, tivemos respostas e comentários como os transcritos adiante. Uma delas diz respeito à expressão "tirar o cavalinho da chuva", cuja interpretação evoca a idéia de frustração, desistência ou abandono de algum propósito ou intenção. Em "Pode tirar seu cavalinho da chuva porque eu não sairei com você", por exemplo, a expressão que apresenta função predicativa, como em "tire seu cavalinho da chuva" aparece exercendo a função de objeto direto, acompanhando o verbo poder, que dá ênfase ao enunciado no qual a expressão comparece.

Outra expressão presente no protocolo de estudos a que nos referimos acima é "chá de cadeira", que se apresenta como um sintagma nominal e exerce a função de objeto direto, veiculando a idéia de enfado ou cansaço causado por uma expectativa ou espera excessiva, inútil ou vã, como em "O dentista me deu um chá de cadeira".

O provérbio em foco nos dados transcritos a seguir é "Feliz foi Adão que não teve sogra" que, ao veicular a idéia de uma felicidade advinda da inexistência de sogra, que não raras vezes é tida como megera em nossa sociedade, evoca distintos conhecimentos (enciclopédico, pressuposicional, semântico, cultural, etc.) para ser lido na chave textual paremiológica.

Vejamos inicialmente algumas reações de uma senhora afásica, MG, a duas expressões formulaicas a ela apresentadas.

(1) MB a outra expressão é "tirar o cavalinho da chuva". O que queremos dizer com isso? ((12s))

MG quando que... ela tá conversando com alguém e... ah...((9s)) chá/ tá ((13s)) o coração ((ri, aparentemente por conta da evocação lexical inesperada)) Fala ((13s)) " tira o cajadinho da chave"... NÃO!

MB [chuva!

MG É ((risos de $M B$ e $M G))$ 
MB mas porque uma pessoa diz "tira o cavalinho da chuva"? ((4s)) "pode tirar o cavalinho da chuva"?

MG quando não quer nada...

MB quando não tá a fim...

MG ISSO!

(2) MB A outra é 'chá de cadeira'...

MG É quando alguém ((4s)) você tá LÁ ((3s)) na.. daí ((4s))todo mundo sai... exceto você...

MB Aí você fica lá...

MG ((sentada na cadeira, MG realiza uma pantomima, encenando com o corpo e a expressão facial a atitude de alguém entediado))

MB Cansada?

MG Cansada de FICAR... sem ninguém te chamar

Esses dois extratos assinalam os movimentos interpretativos de MG. A partir deles, podemos observar a presença de alterações afásicas metalingüísticas, como longas pausas, dificuldades de evocação, simplificação da complexidade sintática e produção de parafasias morfofonológicas. Também podemos observar as reações de MG às suas dificuldades, por meio de autocorreções e reparos, de determinados aspectos prosódicos e da riqueza de gestos corporais. Observamos ainda como ela procede de forma metaenunciativa no reconhecimento e na manipulação do sentido da expressão formulaica, evocando - nos dois exemplos - uma situação de emprego ou de uma cena enunciativa a ela atinente. A familiaridade semântico-pragmática com a expressão idiomática pode ser assinalada ainda por meio da função anafórica (encapsuladora) de "isso", no exemplo (1), com o qual MG recupera de forma discursivo-cognitiva (cf. $\mathrm{KOCH}, 2004$ ) o referente, servindo-se para tanto do segmento do turno precedente de MB.

Vejamos agora a reação de uma senhora, IG, diagnosticada como portadora de uma Doença de Alzheimer em estado inicial. No extrato a seguir podemos observar como IG, com a intervenção da interlocutora, constrói de maneira conjunta a interpretação da expressão formulaica, valendo-se também da remissão a uma cena enunciativa ou situação de emprego, passando, para tanto, do plano da menção para o plano enunciativo do uso. 
(3) EM A expressão é "tirar o cavalinho da chuva".

IG hum hum((6s)) tá chovendo e eu moro numa fazenda em que tenha cavalo eu vou lá pego o cavalo e tiro, protejo pra ele não tomar chuva né?

EM hum hum...pra ele não ficar molhado...

IG isso

EM mas também a gente pode imaginar outros contextos né? Outros usos pra essa expressão...

IG hã?

EM falar "tirar o cavalinho da chuva" e de repente não tem nem cavalo na jogada...

IG $(($ risos $))$

EM é uma expressão metafórica

IG é é...então ((5s)) o caso é é o seguinte ((4s)) vamos "tirar o cavalo da chuva"...

EM isso

IG [pra fazer o seguinte...

EM diga...

IG é ((4s)) "tirar o cavalinho da chuva"? (4s) não me ocorre...

EM em que contexto a gente pode usar?

IG é $((5 s))$

EM [quando alguém fala "ah pode tirando o cavalinho da chuva"...Não tem isso?

IG [ah, tem tem sim é...

EM "ah eu vim aqui na sua casa jantar hoje..."

IG humhum

EM aí a senhora fala assim "tira o cavalinho da chuva". Por quê?

IG "eu não vou fazer comida" ((risos)) "eu não vou fazer comida hoje vai ter um lanche" ((risos))

EM então então o que que isso quer dizer?

IG ai ai... agora é que ((risos)) eu enrosco é ((4s)) deixa eu ver... 
EM "pode perder..."

IG "a esperança"

EM “as esperanças" né... quer dizer "não tenha muitas expectativas" né?

IG [é é é

EM eu não tenho muito expectativa então eu vou "tirar meu cavalo" da chuva porque... pra ele não se molhar né porque se eu nutrir...

IG [isso...hum hum

EM expectativas...

IG humhum

EM que não se realizem...

IG [é é verdade

EM pode ser que eu me frustre...

IG é verdade é verdade

Inicialmente, IG parece proceder a uma análise literal da expressão "tirar o cavalinho da chuva". A intervenção de EM após a explicação fornecida por IG, que se refere a uma situação hipotética na qual ela mora em uma fazenda e tira o cavalo durante a chuva para impedir que ele fique molhado, ressalta o que se apreende dessa primeira iniciativa interpretativa. A partir do momento em que EM estimula IG a considerar outros contextos nos quais a expressão - uma "metáfora" - poderia ser utilizada, esta última, após uma reação de estranhamento (“hã?"), atenta ao exemplo invocado por sua interlocutora, constrói de forma cooperativa com ela uma cena enunciativa de uso apropriado da expressão em foco:

EM "ah eu vim aqui na sua casa jantar hoje..."

IG humhum

EM aí a senhora fala assim "tira o cavalinho da chuva". por quê?"

IG "eu não vou fazer comida" ((risos)) "eu não vou fazer comida, hoje vai ter um lanche" ((risos))

Uma vez "solucionado" o problema da compreensão da expressão por meio da evocação de seu emprego em determinado contexto, o problema metalingüístico, se persistente, é reorganizado, desde que surge acompanhado 
de uma postura meta, isto é, de uma atitude reflexiva de IG a respeito de seu significado ("agora é que eu enrosco"; “deixa eu ver..."). IG não deixa de reconhecer suas dificuldades, certamente provocadas ou acentuadas por um tipo de tarefa (isto é, o protocolo de estudos utilizado pela pesquisadora) que, se não é de todo estranho a ela, uma ex-professora, não deixa de ser descontextualizado o suficiente para agregar maior complexidade ao manuseio lingüístico-cognitivo. Vejamos novamente, a propósito, a seguinte passagem do exemplo anterior:

EM então então o que que isso quer dizer?

IG ai ai... agora é que ((risos)) eu enrosco é ((4s)) deixa eu ver...

Tomemos agora o enunciado proverbial "Feliz foi Adão que não teve sogra". Vejamos como reage a ele uma senhora, TS, com Doença de Alzheimer em estado inicial. Se TS, ao contrário de IG, não procede a uma espécie de interpretação literal do provérbio, mostra a tendência intrusiva de relações semântico-pragmáticas irrelevantes, fato que chama a atenção para o papel estruturante do interlocutor, que atua de modo mediador na objetivação da significação.

(4) EM a senhora conhece aquele provérbio, né, "Feliz foi Adão que não teve sogra? ((EM e TE riem $)$ Quando a gente fala esta Expressão... o que que a gente tá...

TS [É porque diz que as sogras são ((4s)) mu:: muito chatas, né?

EM hum hum...e por que que o Adão... justamente o Adão é que foi feliz?

TS porque ele num tinha sogra né, porque...quem fez a mulher dele foi Deus ((EM e TE riem)) e Deus é homem ...ele deve ter tido SOGRO

EM [a senhora ta falando uma coisa interessante aí...

TS eu acho que ele teve sogro mas sogra não teve mesmo não! agora pergunto: por que que Deus é bom e a e a sogra num é? heim?

Diante da expressão, TS assinala para o interlocutor de maneira mais ou menos evidente seus gestos interpretativos: ativa um conhecimento enciclopédico a respeito de quem é Adão; evoca a memória discursiva para ativar pressupostos 
culturais e determinados pré-construídos, como a idéia que se tem das sogras em nosso contexto cultural; procede a inferências semântico-pragmáticas várias (como o reconhecimento de implícitos culturais e objetos investidos de propriedades semânticas, como as relações genro/sogra e marido/mulher); articula os planos enunciativos de menção e uso, identificando o significado da expressão formulaica a partir de seu emprego e das normas pragmáticas a ele relacionadas, bem como de suas regularidades lingüísticas.

O exemplo anterior reforça a tese de que, mesmo que esbarrem em dificuldades de ordem metalinguística, sujeitos afásicos e com Doença de Alzheimer em estados iniciais, precisamente por evocarem instâncias de cristalização sociocognitiva das expressões formulaicas, não chegam a retirar delas as características enunciativas a que historicamente pertencem. Ao buscar o significado do provérbio em questão, TS reconhece - como os falantes "eficazes" - que pode haver algum ganho argumentativo na remissão a uma expressão formulaica/metafórica no lugar de uma forma mais direta ou literal de igual significado ("chutar o balde" no lugar de "rebelar-se", por exemplo):

[É porque diz que as sogras são ((4s)) mu:: muito chatas, né?

Pelos dados que temos obtido em nossos estudos sobre a metaforicidade na fala de sujeitos afásicos ou com Doença de Alzheimer em estado inicial, os sujeitos trabalham metaenunciativamente com o elemento metafórico ao aludirem ao que na língua passa a "fazer sentido" para eles. Desse modo, a referencialidade da relação entre linguagem e realidade, longe de perder-se, pode ser restabelecida de maneira conjunta pelos sujeitos e seus interlocutores. $\mathrm{O}$ fato de nossos dados serem colhidos em situações interlocutivas e não em situações de teste ou avaliação diagnóstica torna-se, desse modo, relevante.

O caráter interacional dos dados que temos estudado tem permitido também que observemos que a linguagem - no contexto patológico - não é em si mais indeterminada do que nos ditos contextos normais de fala. De todo modo, a determinação do sentido parece nesse caso estar mais fortemente ligada à presença do interlocutor e ao seu papel de co-construtor da significação, bem como à qualidade interativa dos interlocutores e à maneira pela qual eles estruturam a dinâmica enunciativa e conversacional. 


\section{Comentários finais}

Como podemos observar em relação aos dados apresentados, os sujeitos que têm patologias como as consideradas aqui, do mesmo modo que os sujeitos que não as apresentam, poucas vezes se reportam, em situações de protocolos de estudo ou entrevistas livres, a uma análise do tipo literal ou definicional da expressão formulaica - ou do elemento metafórico; os sujeitos tendem a um melhor desempenho quando confrontados com uma cena enunciativa pertinente ao seu uso ou quando se reportam a um outro sintagma metafórico tido como um equivalente do ponto de vista semântico-pragmático, indicando que a chave para a interpretação do fenômeno formulaico é mesmo uma "inferência prática no mundo", como afirma Parret (1998).

Nossos dados indicam que, à maneira do que ocorre em contextos não patológicos, sujeitos com afasia e com Doença de Alzheimer não apenas procedem a uma espécie de "cálculo metafórico" da identificação do significado da expressão a partir de uma situação de uso e da observação de normas pragmáticas a ela relativas: nossos dados mostram também que a metaforicidade é apreendida pelos sujeitos com o concurso de outros processos cognitivos e com base em expectativas interpretativas que eles nutrem em relação às regularidades lingüísticas referentes ao "cálculo" aludido acima (cf. MOURA, 2005).

Nossos dados indicam ainda que a não-consideração mútua e constitutiva de aspectos verbais e não-verbais na significação certamente pode levar a uma dificuldade no tratamento da metaforicidade; ao indicarem que a metaforicidade depende de vários processos interativos (entre linguagem e realidade, entre os sujeitos interactantes, entre processos verbais e não-verbais), dados como os que aqui são apresentados apontam para uma necessidade de superação de dicotomias como as que envolvem o lingüístico e o cognitivo no entendimento das patologias de linguagem e no próprio entendimento do fenômeno metafórico. Isso se mostra particularmente importante para o questionamento da idéia de que o elemento metafórico - cujo significado é apenas enunciativamente assinalado na língua, obrigando os sujeitos a "trabalharem" sociocognitivamente sobre ele seria inteiramente apreendido no/pelo sistema lingüístico ou, pelo contrário, darse-ia exteriormente à sua realidade estrutural e funcional, isto é, por meio de algum tipo de insight ou de um sistema conceptual de natureza essencialmente mental, psicológica (cf. MOURA, 2005). 
Nos dois contextos aqui focalizados, a linguagem, em seu percurso sociocognitivo, desenvolve papel crucial na identificação e na reconstituição da metaforicidade. A tomada dos dois contextos - afásico e demencial - torna-se, pois, importante para entendermos melhor o papel organizador e mediador exercido pela linguagem na emergência, consolidação ou reorganização de uma competência lingüístico-interacional, sociocognitiva, essencial para o trabalho com e sobre o sentido. Temos percebido que a crucial importância da observação dos fenômenos enunciativos no contexto patológico para a reflexão lingüística reside no fato de que os dados da patologia confrontam (e não contrariam) o que acontece no discurso normal, se entendermos que há continuidade e não mera ruptura entre normalidade e patologia (MORATO et al., 2005).

Ainda que os problemas de linguagem se devam a causas diferentes e estejam relacionados a diferentes contextos patológicos, deixam entrever várias semelhanças semiológicas e semelhantes formas de enfrentamentos das dificuldades lingüísticas por parte dos sujeitos. A comparação mais consistente de dados de afasia e Doença de Alzheimer certamente permitirá que aprofundemos nossos conhecimentos a respeito da especificidade e da generalidade dos procedimentos levados a cabo pelos sujeitos, com ou sem patologias cognitivas, diante dos "mistérios da significação".

Na tarefa de apreensão e manipulação da metaforicidade constitutiva das expressões formulaicas, sujeitos com afasia e com Doença de Alzheimer não deixam de nos apontar - à maneira dos sujeitos que não apresentam patologia de linguagem - como desenvolvem durante a enunciação estratégias de compreensão e de (re)construção de sentidos. Certamente, isso exige dos falantes algum domínio de competências relativamente à linguagem (metalingüísticas, metaenunciativas, metaformulativas, metadiscursivas), como também de uma série de processos de ordem sociocognitiva, pragmática, interacional.

Para concluir, vale mencionar ainda duas reações extremamente interessantes diante das expressões formulaicas que podem testemunhar a solidariedade sociocognitiva entre um saber a língua e um saber o mundo: em relação à expressão "caiu na rede é peixe", disse à interlocutora uma senhora com Doença de Alzheimer, entre risos: "Ah, eu num sei...eu sei dizer que o namorado SEMPRE falava isso! ((4s)). Por que mesmo? ((risos))". Em face da perplexidade causada pelo tipo de afasia que o acometeu, em que preponderavam as dificuldades de acesso lexical, questiona-se um senhor, balaieiro de profissão, 
revelando uma percepção ao mesmo tempo metafórica e escatológica da linguagem: "Por que, heim, por que é que as palavras não caem mais do се́u?"

Como diria Bertolt Brecht: "tantas perguntas, tantas respostas...".

\section{Notas}

${ }^{1}$ Tomada em um sentido largo, a perspectiva sociocognitiva, dentro da qual podemos abrigar tanto o sociointeracionismo vygotskiano quanto a Lingüística Cognitiva californiana, evoca entre seus postulados os seguintes pontos: i) a linguagem é indissociável de outros aspectos da cognição humana; ii) a linguagem é resultado de uma interação de diferentes fatores "internos" (inerentes à condição do ser humano e ao funcionamento do mundo) e "externos" (inerentes às nossas experiências de/ no mundo). Cada um desses fatores (físicos, biológicos, comportamentais, psicológicos, sociais, culturais, comunicativos) pode ser uma fonte de restrições e condições para aquisição, evolução, estrutura e uso da linguagem.

${ }^{2}$ A tradição estruturalista dividiu as afasias em dois grandes tipos: fluentes e nãofluentes, anteriores e posteriores, motoras e sensoriais. As primeiras têm como características os problemas de expressão (como alterações fonético-fonológicas, estereotipias, perseverações, disprosódias, parafasias - sobretudo fonológicas -, fala telegráfica, agramatismo, falta de iniciativa verbal, alteração de linguagem escrita, apraxia bucolabiolingual) e são creditadas a lesões adquiridas na parte anterior do córtex cerebral; as segundas têm como características problemas de compreensão, ausência de déficits articulatórios e alteração nos aspectos semânticos da linguagem (como anomias, dificuldades de evocar ou selecionar palavras, dificuldades maiores com a linguagem escrita, parafasias - sobretudo semânticas -, circunlóquios, confabulações). Os problemas perceptivos e gestuais são mais freqüentes e numerosos nesse tipo de afasia, que é creditada a lesões adquiridas na parte posterior do córtex cerebral (cf. MORATO, 2001b).

${ }^{3}$ Descrita pelo alemão Aloïs Alzheimer em 1906, a Doença de Alzheimer se traduz por alterações cognitivas e comportamentais que constituem uma síndrome demencial associada à presença de lesões histológicas características (cf. DÉFONTAINES, 2001, p. 37). Trata-se do tipo mais comum entre as demências, atingindo dois terços das que são diagnosticadas. Entre suas causas podemos encontrar fatores genéticos, fatores de risco (antecedentes mórbidos como traumatismos cranianos com perda de consciência, arteriosclerose e diabetes) e 
depressões tardias, não tratadas. No campo dos estudos neurocognitivos, entendese em linhas bem gerais que a Doença Alzheimer (doravante, DA) evolui em três fases: a forma leve, na qual os problemas mnésicos são constantes; a forma moderada, na qual os problemas mnésicos passam a ser incapacitantes, seguidos de desorientação têmporo-espacial e lingüística (nesta fase, os problemas de linguagem, ainda não presentes na forma anterior, passariam a ser freqüentes e prontamente perceptíveis. Somados a eles, os problemas práxicos e gnósicos configurariam o que é chamado por muitos autores de síndrome afásico-apráxicoagnósica); a forma severa, na qual a memória se encontra gravemente alterada e a linguagem apresenta-se sensivelmente comprometida. Com relação aos problemas de linguagem na DA, num primeiro estágio, seriam identificados déficits na atividade de nomeação, repetições, circunlóquios, uso expressivo de dêiticos e de estruturas sintáticas consideradas "simples", sem alterações de linguagem no nível articulatório - ainda que as pausas e as hesitações sejam consideradas recorrentes. Todos esses problemas, classicamente, têm sido atribuídos a um déficit mnésico (em especial, a um déficit de memória semântica) ou a uma alteração de consciência; num segundo estágio, o sujeito com DA apresentaria um agravamento de problemas tanto no processamento sintático quanto no semântico; no estágio final, as habilidades lingüísticas gerais do sujeito estariam gravemente comprometidas, chegando por vezes ao mutismo.

${ }^{4}$ Para Damasceno (2000), interessado no diagnóstico diferencial de envelhecimento e de senilidade, os indivíduos podem apresentar no processo de envelhecimento normal, por motivos variados, dificuldades de linguagem, principalmente de ordem semântico-lexical e de ordem discursivo-pragmática . Segundo ele, a semelhança entre o que pode ocorrer no envelhecimento e os estágios iniciais de DA causaria dificuldade diagnóstica da demência não apenas em relação ao envelhecimento normal, como também em relação à semiologia apresentada nos quadros de afasias posteriores - isso porque as afasias de Wernicke, cujo sintoma mais evidente são os problemas de compreensão da linguagem, estariam mais próximas em termos sintomatológicos das demências. Na verdade, são duas as dicotomias comumente produzidas no campo das pesquisas clínicas: uma, em torno dos processos de produção e de compreensão da linguagem, via dicotomia Afasia de Wernicke $\mathrm{x}$ Afasia de Broca; outra, em torno do diagnóstico diferencial das afasias e das demências, feito nos termos a que nos referimos acima.

5 "Les stéréotypes linguistiques sont des expressions figées, allant d'un groupe de deux ou plusieurs mots ensemble à des syntagmes entiers et même à des phases" (1999, p. 2). 
${ }^{6}$ A afirmação se justifica, entre outras coisas, em função do fato de que é possível evocar, no tocante aos vários processos figurativos da linguagem (como metáforas lexicais, idiomatismos, provérbios, slogans, etc.), diferentes graus de metaforicidade, de cristalização formal e discursiva, de regularidades lingüísticas, de co-existência de processos cognitivos, etc. Alguns estudos a respeito do tratamento da metáfora por sujeitos com Demência de Alzheimer têm afirmado (cf. PAPAGNO, 2001) que, se é verdade que esses sujeitos podem apresentar na fase inicial uma capacidade preservada de interpretar expressões idiomáticas, isso não aconteceria com a interpretação de metáforas. Segundo tais estudos, esses sujeitos teriam a tendência de interpretar de forma literal expressões metafóricas. Considerando que estudos desse tipo ainda deveriam ser aprofundados, os autores postulam, todavia, que a explicação para os achados obtidos nos protocolos que utilizam estaria na diferença - não suficientemente esclarecida - entre metáfora e idiomatismo, por exemplo, tidas como distintas linguagens figurativas que dependeriam distintamente da memória (cf. SWINNEY; CUTLER, 1979; ORTONY, 1979; TABOSSI; ZARDON, 1995).

${ }^{7}$ Quanto a este ponto, admitimos, como Kleiber (2000) e outros, a existência de provérbios com sentido mais metafórico e menos metafórico. Como exemplos de provérbios mais metafóricos, podemos pensar em "Cada macaco no seu galho" ou "A pressa é inimiga da perfeição"; como provérbios menos metafóricos, podemos pensar em "A união faz a força" ou "Roma não foi feita num dia".

\section{Referências Bibliográficas}

AMOSSY, R.; PIERROT, A. H. Stéréotypes et clichés: langue, discours, société. Paris: Nathan Université, 1997.

AUTHIER-RÉVUZ, J. As palavras incertas. Campinas: Ed. da Unicamp, 1998.

BOLDRINI, M. As expressões formulaicas na linguagem de sujeitos afásicos: um estudo dos idiomatismos. (Relatório de Pesquisa de Iniciação Científica orientado por Edwiges Maria Morato - FAPESP), 2004.

BOTTINI, G.; CORCORAN, R.; STERZI, R.; PAULESU, E.; SCHENONE, P.; SCARPA, P. et al. The role of the right hemisphere in the interpretation of figurative aspects of language. A positron tomography activation study. BRAIN 117, p. 1241-1253, 1994.

CAZELATO, S. E. A interpretação de provérbios equivalentes por afásicos: um estudo enunciativo. 2003. Dissertação (Mestrado) - IEL/Campinas, 2003. 
DAMASCENO. B. P. Avaliação da linguagem do sujeito idoso. In: FORLENZA, O. V; CARAMELLI, P. (Ed.). Neuropsiquiatria Geriátrica. São Paulo: Atheneu, 2000. DÉFONTAINES B. Les démences. Paris: MED-Line Éditions, 2001.

FAUCCONNIER, G.; TURNER, M. The Way We Think: Conceptual Blending and the Mind's Hidden Complexities. New York: Basic Books, 2002.

KLEIBER, G. Sur les sens des proverbs. Langages 139, p. 39-58, 2000.

KOCH, I. G. V. Introdução à Lingüística Textual. São Paulo: Ática, 2004.

LAKOFF, G. Les universaux de la pensée métaphorique: variations dans l'expression linguistique. In: FUCHS, C.; ROBERT, S. (Ed.). Diversité des langues et représentations cognitives. Paris: Ophrys, 1997.

LAKOFF, G.; JOHNSON, M. Philosophy in the flesh. NY: Basic Books, 1999.

MARCUSCHI, L. A. Do código para a cognição: o processo referencial como atividade cognitiva. Veredas 10: p. 43-62, 2003.

MONDADA, L. Cognition et parole-en-interaction. Veredas 10: p. 131-39, 2003.

MORATO, E. M. Linguagem e Cognição - As reflexões de L.S. Vygotsky sobre a ação reguladora da linguagem. São Paulo: Plexus, 1996.

MORATO, E. M. (In)determinação e subjetividade na linguagem de afásicos: a inclinação anti-referencialista dos processos enunciativos. Cadernos de Estudos Lingüísticos 41: p. 55-74. 2001a.

MORATO, E. M. Neurolingüística. In: MUSSALIN, F.; BENTES, A. C. (Ed.). Introdução à Lingüística: domínios e fronteiras. Ed. Cortez, 2001b. V. 2.

MORATO, E. M. Metalinguagem e referenciação: a reflexividade enunciativa nas práticas referenciais. In: KOCH, I.G.V.; MORATO, E.M.; BENTES, A. C. (Ed.). Referenciação e discurso. São Paulo: Contexto, 2005a.

MORATO, E. M. Aspectos sócio-cognitivos da atividade referencial: as expressões formulaicas. In: MIRANDA, N.S.; NAME, M.C. (Ed.). Lingüística e cognição. Juiz de Fora: Editora UFJF, 2005b.

MORATO, E. M. et al. Análise da competência pragmático-discursiva de sujeitos afásicos que frequientam o Centro de Convivência de Afásicos (CCA-IEL/ UNICAMP). Relatório Final de Pesquisa (FAPESP - Proc. 03/02694-9), 2005.

MOURA, H. M. Linguagem e cognição na interpretação de metáforas. Veredas 10, p. 153-161, 2003 
MOURA, H. M. Metáfora e regularidades lingüísticas. In: MIRANDA, N. S.; NAME, M. C. (Ed.). Lingüística e Cognição. Juiz de Fora: Editora UFJF, 2005.

ORTONY, A. Beyond literal similarity. Psychological Review 86, p. 161-180, 1979.

PAPAGNO, C. Comprehension of metaphors and idioms in patients with Alzheimer's disease - A Longitudinal study. Brain 124, p. 1450-1460, 2001.

PARRET, H. Enunciação e pragmática. Campinas: Ed. da Unicamp, 1998.

PIRES DE OLIVEIRA, R. 'A Manhã é uma esponja': Um estudo sobre a engenhosidade semântica. DELTA (13) 2, 1997.

PLANTIN, C. Lieux communs, topoï, stéréotypes, clichés. Paris: Kimé, 1993.

SALOMÃO, M. M. A questão da construção do sentido e a revisão da agenda dos estudos da linguagem. Veredas: 3(1), p. 61-79, 1999.

SCHAPIRA, Ch. Les stéréotypes en français: proverbes e autres formules. Paris: Ophrys, 1999.

SWINNEY, D. A.; CUTLER, A. The access and processing of idiomatic expressions. Journal of Verbal Behaviour 18, p. 523-534, 1979.

TABOSSI, P.; ZARDON, F. The activation of idiomatic meaning. In: EVERAERT, M. et al. (Ed.). Idioms: structural and psychological perspectives. Hillsdale (NJ): Lawrence Erlbaum, 1995.

VYGOTSKY, L.S. Thinking and Speech - The collected works of L.S. Vygotsky. (Vol.I). Rieber, R. \& Carton, A. (Ed.). NY: Plenun Press, 1987 (original de 1934). 